\title{
Mannitol 1-Phosphate Metabolism Is Required for Sporulation in Planta of the Wheat Pathogen Stagonospora nodorum
}

\author{
Peter S. Solomon, Kar-Chun Tan, and Richard P. Oliver \\ Australian Centre for Necrotrophic Fungal Pathogens, SABC, Murdoch University, Perth 6150, Western Australia, Australia \\ Submitted 17 May 2004. Accepted 8 September 2004.
}

\begin{abstract}
An expressed sequence tag encoding a putative mannitol 1phosphate dehydrogenase (Mpd1) has been characterized from the fungal wheat pathogen Stagonospora nodorum. Mpd1 was disrupted by insertional mutagenesis, and the resulting mpdl strains lacked all detectable NAD-linked mannitol 1-phosphate dehydrogenase activity (EC 1.1.1.17). The growth rates, sporulation, and spore viability of the mutant strains in vitro were not significantly different from the wild type. The viability of the mpdl spores when subjected to heat stress was comparable to wild type. Characterization of the sugar alcohol content by nuclear magnetic resonance spectroscopy revealed that, when grown on glucose, the mutant strains contained significantly less mannitol, less arabitol, but more trehalose than the wildtype strains. The mannitol content of fructose-grown cultures was normal. No secreted mannitol could be detected in wild type or mutants. Pathogenicity assays revealed the disruption of $\mathrm{Mpd} 1 \mathrm{did}$ not affect lesion development, however the mutants were unable to sporulate. These results throw new light on the role of mannitol in fungal plant interactions, suggesting a role in metabolic and redox regulation during the critical process of sporulation on senescing leaf material.
\end{abstract}

Additional keywords: Septoria, Phaeosphaeria.

Mannitol is the most widespread and abundant organic molecule in most ascomycetes and basidiomycetes (Lewis and Smith 1967; Pfyffer et al. 1989), including many fungal plant and animal pathogens (Chaturvedi et al. 1996; Jennings et al. 1998; Joosten et al. 1990). It is also present in a small number of vascular plants (Stoop et al. 1996). Despite its ubiquity and abundance, much debate about its role or roles remains. A role in osmotic adjustment has been suggested (Stoop and Mooibroek 1998) but, both in Cladosporium fulvum (Clark et al. 2003) and Magnaporthe grisea (Dixon et al. 1999), arabitol and glycerol appear to be the main compatible solutes. A role in carbon storage has also been suggested (Witteveen and Visser 1995), but in M. grisea, the main stores in spores are lipid and glycogen (Thines et al. 2000). A role in oxidant defense, via direct radical scavenging (Smirnoff and Cumbes 1989), has been supported by recent experiments in the plant pathogen Alternaria alternata (Jennings et al. 1998, 2002), the human pathogen Cryptococcus neoformans (Chaturvedi et al. 1996), and in yeast (Chaturvedi et al. 1997). Secretion of man-

Corresponding author: R. Oliver; Telephone: +61-8-9360-7404; Fax: +618-9360-6303; E-mail: roliver@murdoch.edu.au nitol is thought to directly protect the invading pathogens by quenching host-produced reactive oxygen species (Jennings et al. 2002), although it was noted that not all pathogens secrete mannitol (Daub and Ehrenshaft 2000).

Studies on the metabolism of mannitol in filamentous fungi are sparse. Hult and associates (Hult and Gatenbeck 1978, 1979; Hult et al. 1980) suggested that mannitol participates in a metabolic cycle involving the conversion of fructose 6-phosphate to mannitol 1-phosphate via a NAD-linked dehydrogenase (EC 1.1.1.17), dephosphorylation using a mannitol 1phosphate phosphatase (EC 3.1.3.22), oxidation to fructose, using an NADP-linked mannitol 2-dehydrogenase (EC 1.1.1.138), and finally, phosphorylation to fructose-6-phosphate, using hexokinase (EC 2.7.1.1). The net result of the cycle (Fig. 1) would be transhydrogenation from NADH to NADPH and the consumption of one ATP molecule. Mannitol 1-phosphate 2-dehydrogenase enzyme activity has been described in a number of fungal species (Aitken et al. 1969; Hankinson and Cove 1974; Lewis and Smith 1967; Suvarna et al. 2000; Wang and Le Tourneau 1972; Yamada et al. 1961), and recently, the gene encoding the enzyme was cloned and characterized from Aspergillus niger (Ruijter et al. 2003).

In an effort to characterize genes required for pathogenicity, we recently commenced an expressed sequence tag (EST) library analysis of the important necrotrophic fungal wheat pathogen, Stagonospora (syn. Phaeosphaeria, Septoria, Leptosphaeria) nodorum. An EST with homology to eukaryotic mannitol 1-phosphate dehydrogenase genes was isolated and used to characterize the role of the gene and mannitol in fungal growth and pathogenicity.

\section{RESULTS}

Cloning and sequence analysis of Mpd1.

An EST library of fungal genes expressed in mycelium grown on wheat cell walls has been produced (Solomon et al. 2003). One cDNA was fully sequenced and found to encode an open reading frame predicting a protein of 390 amino acids (AY547308). Blastp searches of the NCBI nonredundant database revealed several convincing matches to filamentous fungal genes, including Alternaria alternata (AAQ63948), which was $87 \%$ identical, Paracoccidioides brasiliensis (AAO47089), Aspergillus nidulans (EAA57724), Neurospora crassa (EAA33240), and M. grisea (EAA46809), all demonstrating between 58 to $65 \%$ identity. However, the products of these genes have not been characterized. At the time of analysis, the best matches ( 40 to $50 \%$ identity) to genes encoding products of known function were to Q9K681 and Q45421. These encode mannitol 1-phosphate dehydrogenases from the bacteria Bacil- 
lus halodurans and Geobacillus stearothermophilus. On this basis, the gene was named Mpdl. More recently, a gene encoding a mannitol 1-phosphate dehydrogenase, $M p d A$ (AY081178), was cloned and characterized from Aspergillus niger. The MpdA protein sequence was $60 \%$ identical to Mpd1.

The predicted protein sequence contains both NAD-interacting domains (GXGXG) and a [LIVMY]-x-[FS]-xx-[STAGCV]$\mathrm{x}$-V-D-R-[IV]-X-[PS] mannitol 1-phosphate dehydrogenase motif at amino acid 150 .

\section{Disruption of $\mathrm{Mpd1}$.}

To establish the role of Mpd1 in S. nodorum, a gene disruption vector was constructed by in vitro transposition (Fig. 2) in which the Mpdl coding region was interrupted 354 bp downstream of the predicted translational start site by the hygromycin cassette. The resulting knockout construct was called pGPSH-Mpd8. The vector was transformed into $S$. nodorum protoplasts, and 60 hygromycin-resistant colonies were collected. Spore polymerase chain reaction (PCR) was used to screen the transformants; two strains, $S$. nodorum mpdl-1 and $m p d 1-53$, were found to have undergone gene replacement as expected. Homologous recombination in these two strains was confirmed by Southern analysis (data not shown). A third strain, S. nodorum Mpd1-17, resulting from an ectopic insertion of the vector, was retained as a control.

\section{Characterization of enzyme activities.}

Enzyme activities were measured in cell-free, desalted protein extracts of $S$. nodorum SN15 (wild type), mpd1-1, mpd153, and Mpd1-17. The wild-type extract was found to oxidize NADH upon addition of fructose 6-phosphate. Maximum activity (1.9 $\mathrm{U}$ per $\mathrm{mg}$ of protein) was obtained with $2 \mathrm{mM}$ fructose 6-phosphate and $2.5 \mathrm{mM} \mathrm{NADH}$. NAD ${ }^{+}$reduction was also observed upon addition of mannitol 1-phosphate with an activity of $0.25 \mathrm{U} / \mathrm{mg}$. These activities were present at similar levels in the ectopic strain. Both mutant strains mpdl-1 and mpd1-53 lacked all detectable activity in both directions. The mutant extracts had normal levels of 6-phosphogluconate dehydrogenase and mannitol dehydrogenase (EC 1.1.1.138) activity, indicating that the effect on mannitol 1-phosphate dehydrogenase was specific (data not shown).

\section{Determination of neutral polyol and sugar concentrations.}

${ }^{13} \mathrm{C}$ nuclear magnetic resonance (NMR) is a convenient method to estimate the concentration of sugars and sugar alcohols in extracts. Methanolic extracts of fungal mycelium

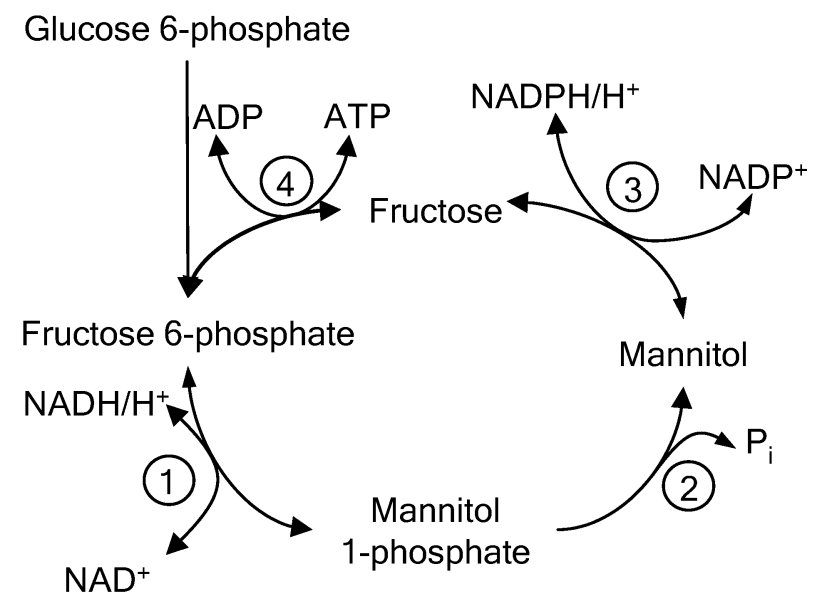

Fig. 1. Proposed mannitol cycle in fungi. 1, Mannitol 1-phosphate dehydrogenase; 2, mannitol 1-phosphate phosphatase-assumed to be irreversible; $\mathbf{3}$, mannitol dehydrogenase; and $\mathbf{4}$, hexokinase. grown initially in minimal medium (MM) with glucose were obtained, and spectra were measured. The spectra were dominated by peaks attributed to glucose in all cases, consistent with carryover of unused media (Fig. 3; Table 1). The wildtype and Mpd1-17 extracts had similar spectra in which peaks consistent with mannitol were clearly visible (only wild type is shown). In addition, lower peaks attributed to arabitol and a trace of glycerol were also present. No trehalose was present. The spectra from the two mutant extracts were very similar to each other but very different from the wild-type extracts (only mpdl-1 is shown). The most prominent peaks were attributed to trehalose; smaller peaks indicated the presence of significant amounts of glycerol. Mannitol was observed but at about $20 \%$ of the level found in the wild-type strains. Arabitol was absent.

The most striking result from the NMR study was that mannitol was reduced but still detectable in the mutant strains. To investigate this further, the $\mathrm{SN} 15$ and $m p d l-1$ strains were grown on fructose and extracts made as before. In this case, the spectra were both very similar; mannitol was abundant, but trehalose was absent.

\section{In vitro growth characteristics.}

In view of the reported role of mannitol in stress metabolism (Ruijter et al. 2003), we next tested the in vitro growth rates and behavior of the mpdl strains in stressed and nonstressed conditions. The appearance, radial growth rate, and germination on CZV8CS media of all strains were identical. Sporulation of the mutants on either CZV8CS or MM was found not to differ significantly to that of the wild-type or ectopic strains in either quantity or timing (Fig. 4). The growth rate in liquid media containing sublethal concentrations of $\mathrm{NaCl}, \mathrm{H}_{2} \mathrm{O}_{2}$, and the fungicide azoxystrobin were unaltered. Furthermore, growth rates in media containing glucose, sucrose, mannitol, trehalose, fructose, and oleate as sole carbon sources were normal as was growth in glucose media supplemented with casamino acids or lacking nitrate (data not shown).

The viability of the $m p d l$ spores upon stress treatment was also investigated. Wild-type and $m p d l-1$ spores were incubated at 40 or $50^{\circ} \mathrm{C}$ or in the presence of $1 \mathrm{mM} \mathrm{NaOCl}$ for $2 \mathrm{~h}$ with samples taken at specified intervals. The samples taken were diluted and plated out, and the colonies that had formed one week later were counted. No colonies developed from spores incubated either at $50^{\circ} \mathrm{C}$ or in $1 \mathrm{mM} \mathrm{NaOCl}$ (data not shown), suggesting that these treatments were too harsh to look for viability differences between the wild-type and $m p d l$ spores. For the spores incubated at $40^{\circ} \mathrm{C}$, approximately $65 \%$ of the SN15 and $m p d 1-1$ spores were viable after a 15 -min heat treatment (Fig. 5). This number decreased to $40 \%$ after $30 \mathrm{~min}$ and then

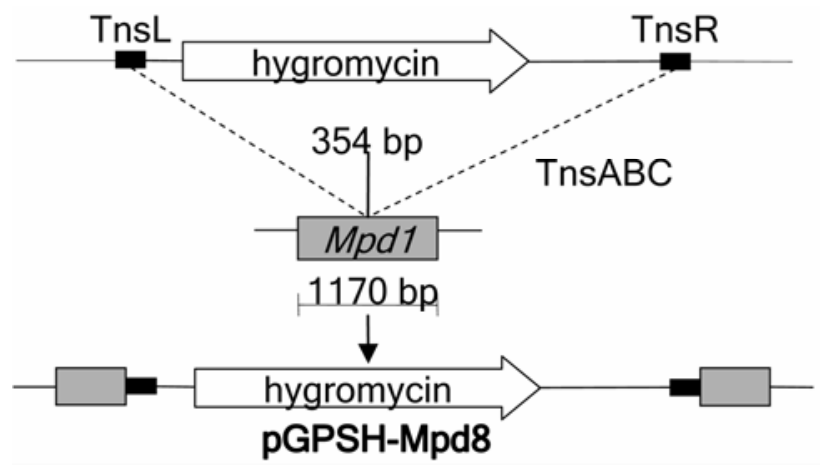

Fig. 2. Diagram outlining the construction of the knockout vector pGPSHMpd8. Note the transposon inserted at 354 bp downstream of the predicted start site, as determined by sequencing using primers homologous to the transposon ends, TnsL and TnsR. 
to $5 \%$ after $60 \mathrm{~min}$. No spores were viable from either strain after $120 \mathrm{~min}$ at $40^{\circ} \mathrm{C}$. There was no significant difference in spore viability at $40^{\circ} \mathrm{C}$ when comparing the SN15 and $m p d l-1$ strains, indicating the disruption of $m p d l$ does not affect spore tolerance to heat stress.

\section{In planta characteristics.}

Symptom development was observed using two types of pathogenicity assay. The first comprised a detached leaf assay in which drops of spores were placed on wheat leaves incubated in benzimidazol agar; the rate of lesion spread was then measured over a period of seven days. The second involved spraying spore suspensions onto intact seedlings, covering the plants for $48 \mathrm{~h}$. and then assaying visual symptoms 7 days postinoculation. For both these assays, the rate of necrotic lesion development caused by the mutant and wild-type strains was not significantly different. The $m p d l$ strains were then examined for their ability to sporulate in planta by allowing the detached leaf assay to continue to the stage of sporulation (Fig. $6)$. At 10 days postinoculation, pycnidia were clearly evident within the necrotic lesion caused by the $S$. nodorum SN15 and Mpd1-17. In contrast, no pycnidia were apparent for either of the mpdl mutants, indicating that mannitol 1-phosphate dehydrogenase activity is required for $S$. nodorum sporulation during infection. The addition of mannitol and other polyols to the detached leaf assay did not restore sporulation (Fig. 7).

\section{DISCUSSION}

This is the first report functionally characterizing a mannitol 1-phosphate dehydrogenase gene from a phytopathogenic fungus. Recently, a gene encoding a mannitol 1-phosphate dehy-
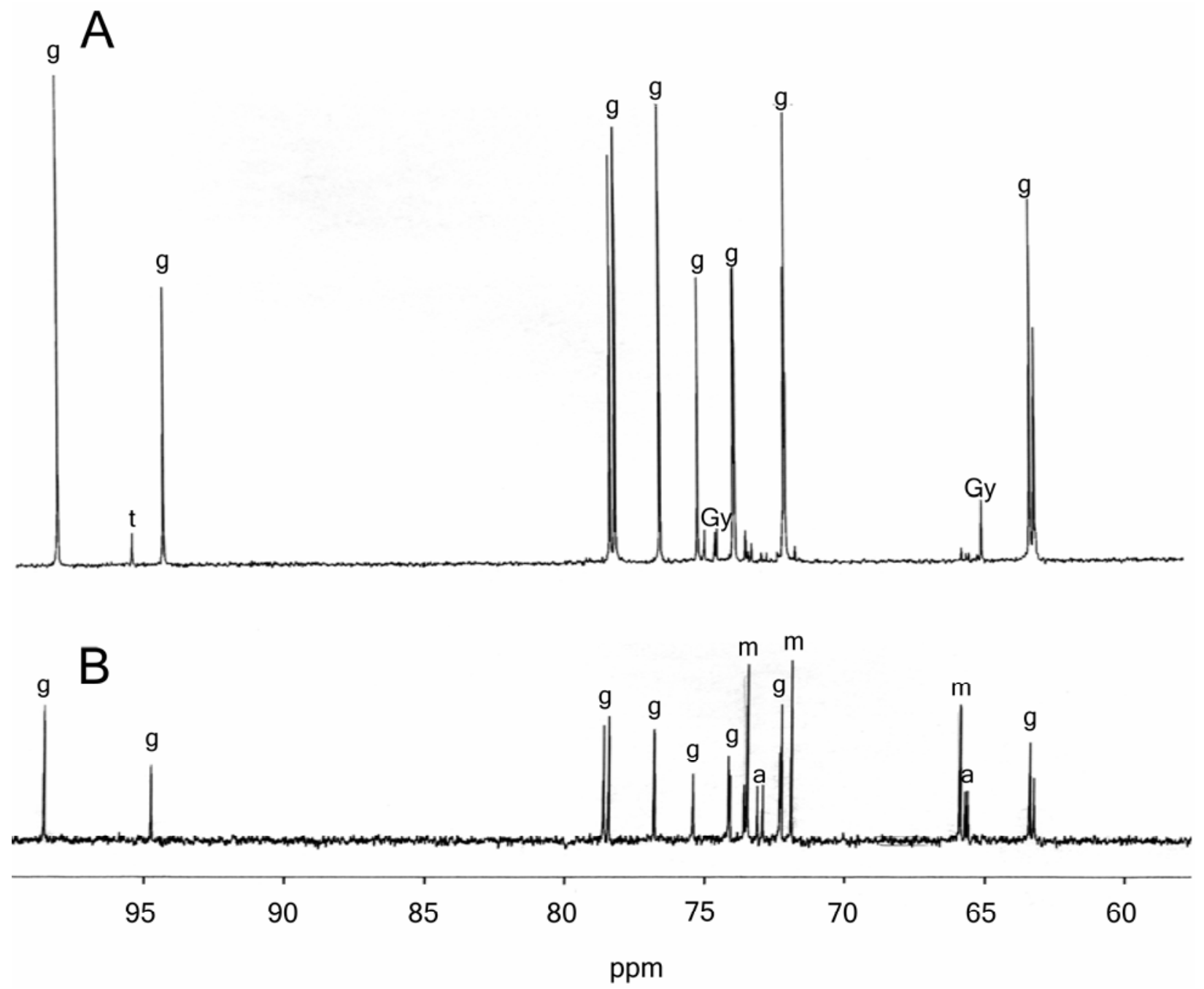

Fig. 3. Nuclear magnetic resonance spectra of methanolic extracts of A, Stagonospora nodorum mpd1-1 and B, S. nodorum SN15. The peaks have been identified and labeled as follows: $\mathrm{a}=$ arabitol; $\mathrm{g}=$ glucose; $\mathrm{Gy}=$ glycerol; $\mathrm{m}=$ mannitol; $\mathrm{t}=$ trehalose. The scales of the spectra are identical.

Table 1. Relative neutral sugar contents of extracts of fungal strains grown on glucose unless stated

\begin{tabular}{lllll}
\hline Polyol & SN15 & Mpd1-17 & mpd1-1 & mpd1-53 \\
\hline Mannitol & 1 & 1 & 0.2 & 0 \\
Arabitol & 0.2 & 0.2 & 0.3 & 0.2 \\
Glycerol & Trace & Trace & 0.4 & 0.3 \\
Trehalose & 0 & 0 & 1 & 0.4 \\
Mannitol when grown on fructose & 1 & ND $^{\mathrm{a}}$ & 0 & ND \\
Trehalose when grown on fructose & 0 & ND & ND \\
\hline
\end{tabular}

${ }^{a}$ Not determined. 
drogenase from the saprobe Aspergillus niger has been characterized (Ruijter et al. 2003). In the saprobe, the gene appears to function to protect conidia from stress. The focus of our study was to determine whether the gene had any role in the pathogenicity of $S$. nodorum.

Enzymic analysis of extracts from the wild-type and $m p d 1$ disrupted mutants showed that the gene encodes an enzyme that interconverts mannitol 1-phosphate and fructose 6-phosphate with NADH as cofactor (EC 1.1.1.17) and that all detectable activity was encoded by the single gene. Maximum activity of the mannitol 1-phosphate dehydrogenase activity was obtained with $2 \mathrm{mM}$ fructose 6-phosphate concentration, which is consistent with reported $\mathrm{K}_{\mathrm{m}}$ values ranging from 0.1 to $2 \mathrm{mM}$ (Aitken et al. 1969; Hankinson and Cove 1974; Lewis and Smith 1967; Suvarna et al. 2000; Wang and Le Tourneau 1972; Yamada et al. 1961). Higher fructose 6-phosphate concentrations inhibited the mannitol 1-phosphate dehydrogenase activity, as was previously reported for the Streptococcus enzyme (Brown and Bowles 1977).

In view of the large amounts of mannitol present in many fungi, it was interesting to determine the effect of gene disruption on the neutral sugar content of the fungus. Our studies show that the mpdl mutant strains contain mannitol. The quantitation is not precise, but our results suggest the mutants contain about $20 \%$ of the wild-type mannitol content when grown on glucose as sole carbon source but normal amounts when grown on fructose. These results indicate that the mannitol in the mutant is synthesized directly from fructose and that this is also likely to happen in the wild type. The source of the mannitol in the mutant when grown on glucose is unclear. It is possible that fructose-6-phosphate is dephosporylated and that the resulting fructose is converted to mannitol. Other possibilities are that glucose is converted to fructose via sorbitol using xylose isomerase or aldehyde dehydrogenase (Holligan and Jennings 1972) or that iditol dehydrogenase converts sorbitol to fructose.

The operation of a mannitol cycle would clearly be impossible in the mutant. The lack of an obvious phenotype, at least in vitro or during vegetative growth in planta, suggests that the

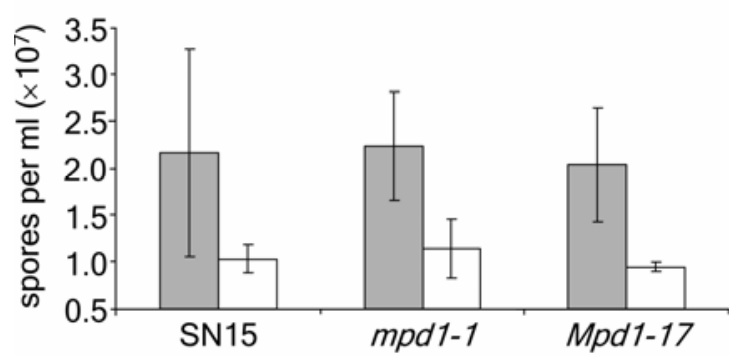

Fig. 4. Total spores produced by Stagonospora nodorum SN15, mpd1-1, and Mpd1-17 on CZV8CS (gray bars) and minimal medium (white bars) agar plates.

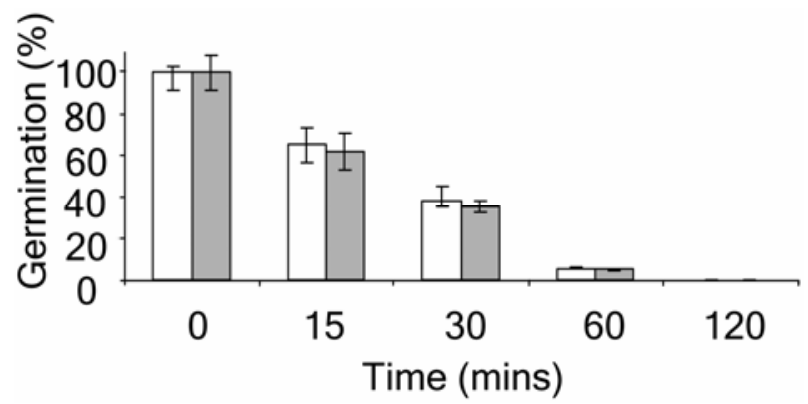

Fig. 5. Graph of spore viability. White bars represent the spore viability of the wild type, while the gray bars represent the mpdl-1 mutant. mannitol cycle either does not operate in this fungus or has no important role. Our data is consistent with the operation of two spurs rather than a cycle. One spur would be the conversion of fructose 6-phoshate via mannitol 1-phosphate to mannitol. The other spur would be from fructose 6-phosphate to fructose and then mannitol. The reversible operation of either spur would consume an ATP but would be neutral with respect to reductant. The operation of either spur would be sufficient to explain the conversion of ${ }^{1} \mathrm{C}$ glucose into ${ }^{6} \mathrm{C}$ in feeding experiments, as has been observed using labeled glucose (Clark et al. 2003; Martin et al. 1985). The metabolism of mannitol via two spurs may mean that each spur can compensate for the lack of activity in the other and that these redundant activities have partially confounded our attempts to define the role of mannitol 1-phosphate dehydrogenase in this study.

We found no alteration in the mutants in their in vitro characteristics, including growth rate and sporulation. Of particular interest was the viability of the mutant spores when subjected to stress conditions. Ruijter and associates (2003) found that the disruption of $M p d A$ significantly affected spore viability upon either heat stress or oxidative stress. Similar stress treatments to those used on A. niger were attempted in this study, however $50^{\circ} \mathrm{C}$ or $1 \mathrm{mM} \mathrm{NaOCl}$ killed all wild-type $S$. nodorum spores after $15 \mathrm{~min}$ of treatment. A $40^{\circ} \mathrm{C}$ heat treatment was attempted and revealed that the inactivation of $m p d l$ did not render the spores more sensitive to heat stress conditions.

Pathogenicity assays showed that the mutants germinated on and infected wheat leaves, producing necrotic lesions. As major carbon sources for the fungus are likely to be either sucrose or fructose and these would supply mannitol to the mutants, we cannot rule out a role for mannitol in pathogenicity. The major phenotype we observed in planta was nonsporulation on leaves. $S$. nodorum is a polycyclic pathogen that only causes significant yield losses in wheat when the flag leaf is heavily infected. This only occurs if the pathogen inoculum can build up during successive cycles of sporulation and reinfection
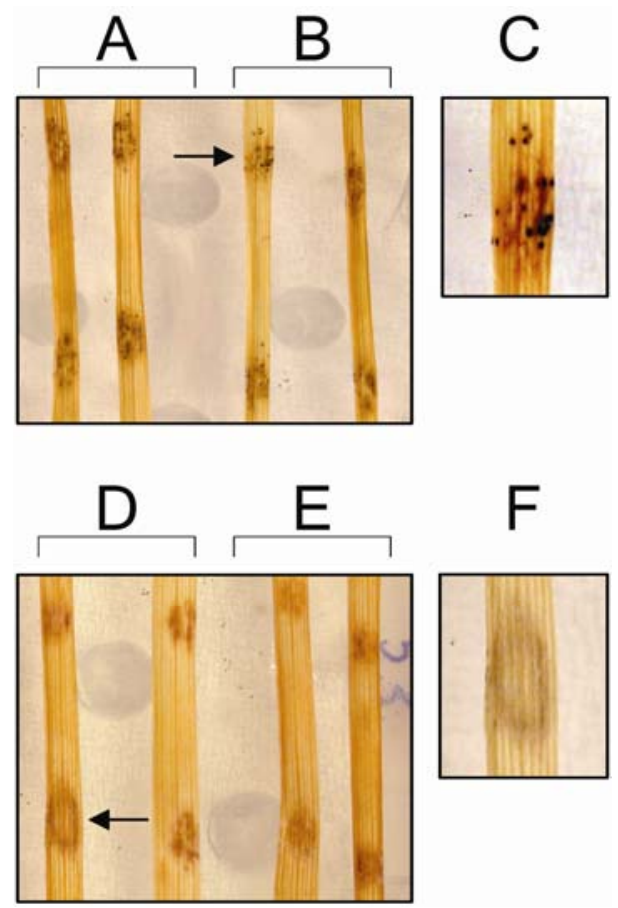

Fig. 6. Photographs of detached leaf assay at 10 days postinoculation. Wheat leaves inoculated with A, SN15 and B, the Mpd1-17. C, Enlargement of the pycnidia visible where the arrow is pointing in $\mathrm{B}$. Wheat leaves inoculated with $\mathbf{D}, m p d 1-1$ and $\mathbf{E}, m p d 1-53$. F, Magnification of the lesion indicated by the arrow in $\mathrm{D}$. 
(Bathgate and Loughman 2001). The ability to rapidly and prolifically sporulate is therefore a key pathogenicity attribute of this pathogen. It appears that mannitol 1-phosphate dehydrogenase has a critical role to play in this process.

The direct cause of the in planta sporulation defect is unclear at this stage. Observation of the sporulation process suggests that leaf senescence is both induced by the pathogen and a prerequisite for sporulation. The defect caused by the lack of mannitol 1-phosphate dehydrogenase activity may hinder the fungus as it kills the leaf and thus prevents metabolism being directed towards sporulation. Experiments are currently underway to determine the role of mannitol metabolism during in planta sporulation.

\section{MATERIALS AND METHODS}

Fungal strains and media.

All fungal growth conditions and media used in this study were as previously described (Solomon et al. 2004).

\section{Disruption of Mpdl.}

The Mpdl cDNA was interrupted through the use of an in vitro transposition reaction as previously described (Solomon et al. 2003). Briefly, $20 \mathrm{ng}$ of a modified pGPS3 vector (New England Biolabs, Beverly, MA, U.S.A.) containing the hygromycin resistance cassette (named pGPS-Hyg) was incubated with $80 \mathrm{ng}$ of the $\mathrm{Mpdl} \mathrm{cDNA}$ at $37^{\circ} \mathrm{C}$ for $1 \mathrm{~h}$. The reaction was stopped at $75^{\circ} \mathrm{C}$ for $15 \mathrm{~min}$, the intact pGPS-Hyg vector destroyed with PI-SceI, and the reaction transformed into Escherichia coli $\mathrm{DH} 10 \mathrm{~B}$. The resulting colonies were analyzed for the presence of the transposon within the Mpdl cDNA by restriction enzyme digestion and sequence analysis.

Preparation and transformation of $S$. nodorum protoplasts. $S$. nodorum protoplasts were prepared and transformed as previously described (Solomon et al. 2004).

\section{Pathogenicity assays.}

Two different pathogenicity assays were used in this study. First, the strains were examined for the ability to infect detached wheat leaves embedded in benzimidazol agar plates, as previously described (Benedikz et al. 1981). Briefly, $2 \mathrm{~cm}$ of the distal end of detached wheat leaves was removed. The next 4- to 5-cm portion was embedded onto benzimidazol agar, adaxial side up. A 5 - $\mu$ inoculum containing $10^{4}$ spores and $0.02 \%$ Tween 20 was placed on the leaves and was incubated under 12-h light and 12-h dark periods at $22^{\circ} \mathrm{C}$, to enable disease development. The size of lesions was measured with a caliper at 7 days postinoculation.

The second pathogenicity assay used in this study was a whole-plant spray. An inoculum was prepared consisting of

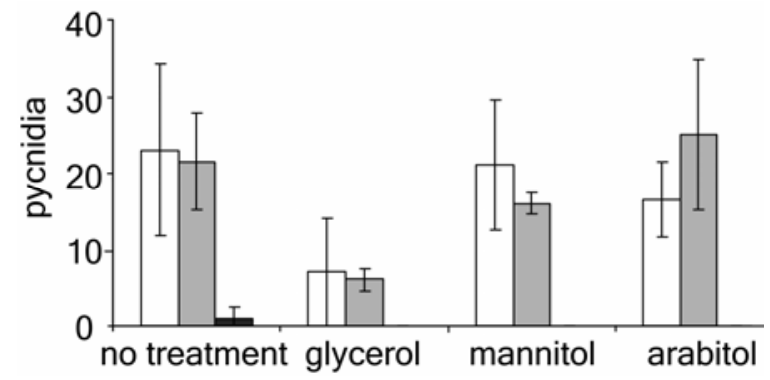

Fig. 7. Pycnidia produced by Stagonospora nodorum SN15 (white bars), Mpd1-17 (gray bars), and mpd1-1 (black bars) on a detached leaf assay in the presence of $10 \mathrm{mM}$ glycerol, mannitol, or arabitol. Note that no pycnidia were detected under any of the conditions examined for $m p d 1-53$.
$10^{6}$ spores per $\mathrm{ml}$ in $0.02 \%$ Tween 20 . Two-week-old wheat seedlings were sprayed twice for $30 \mathrm{~s}$ each time with the inoculum, using a Paasche airbrush paint sprayer (Paasche Airbrush Co., Harwood Heights, IL, U.S.A.). The plants were then allowed to sit for 15 min before the spraying was repeated. After the second spraying, the plants were covered and incubated at $20^{\circ} \mathrm{C}$ in the dark for 2 days, at which point the cover was removed and the plants were grown under normal growth conditions. At 7 days after inoculation, the plants were scored for disease severity. The infections were given a score between 0 and 10, depending on the severity of the infection, with 0 being uninfected and no symptoms of disease and 10 being a completely necrotic dead plant.

\section{Preparation of cell-free extracts and enzyme assays.}

Cell-free protein extracts were prepared as follows. Spores $\left(5 \times 10^{6}\right)$ were inoculated into $100 \mathrm{ml}$ of $\mathrm{MM}(\mathrm{pH} 6.0)$ and were grown as described above for three days. The mycelium was harvested by centrifugation at $3,500 \times g$ for $15 \mathrm{~min}$, with

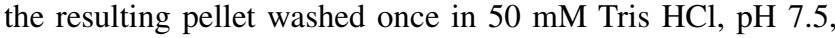
and freeze-dried overnight. The crude protein extract was obtained by grinding the mycelium in a precooled mortar and pestle with $5 \mathrm{ml}$ of $50 \mathrm{mM}$ Tris- $\mathrm{HCl}, \mathrm{pH} 7.5$, containing $0.1 \%$ triton X-100 per gram of dried mycelia. The mycelium was removed from this suspension by centrifugation at $20,000 \times g$ for $5 \mathrm{~min}$, and the supernatant was desalted using a PD-10 column (Amersham Pharmacia Biotech, Piscataway, NJ, U.S.A.).

Mannitol dehydrogenase activity was assayed as previously described (Noeldner et al. 1994). The reaction mixture contained $0.25 \mathrm{mM}$ NADPH, $0.8 \mathrm{M}$ fructose and protein extract. The volume was made up to $1 \mathrm{ml}$ with $20 \mathrm{mM}$ Tris- $\mathrm{HCl}(\mathrm{pH}$ 7.5). One unit was defined as the enzyme activity needed to oxidize $1 \mu \mathrm{mol}$ of NADPH per min at $30^{\circ} \mathrm{C}$. Mannitol 1-phosphate dehydrogenase assay contained $2.5 \mathrm{mM} \mathrm{NADH}$ and 50 $\mu \mathrm{l}$ of protein extract in $50 \mathrm{mM}$ Tris- $\mathrm{HCl}, \mathrm{pH} 7.5$, in a volume of $1 \mathrm{ml}$. The reaction was started with the addition of fructose 6-phosphate to a final concentration of $2 \mathrm{mM}$, unless otherwise stated. One unit was defined as the enzyme activity needed to oxidize $1 \mu \mathrm{mol}$ of NADH per min at $30^{\circ} \mathrm{C}$.

\section{NMR spectroscopy.}

Fungal mycelium was collected by centrifugation from the spent media, was washed once in water, and was weighed, frozen, freeze-dried, and ground in a mortar and pestle. Methanol $(80 \% \mathrm{vol} / \mathrm{vol})$ was used to extract the neutral sugars. Extracts were centrifuged at $18,000 \times g$ for $5 \mathrm{~min}$, and the supernatants were freeze dried. The pellets were resuspended in deuterated water proportionally to the mass of mycelium. ${ }^{13} \mathrm{C}$ natural-abundance spectra were obtained in a $5 \mathrm{~mm}$ probe, using a Bruker Avance $300 \mathrm{Mhz}$ spectrometer. Compounds were identified by reference to known standards. The spectra were dominated by the media carbon source (fructose or glucose), indicating incomplete washing of mycelium. Constituents were quantified by comparing peak heights with that of mannitol in the glucosegrown SN15 sample.

\section{Molecular methods.}

All molecular methods performed within this study were as published by Sambrook and associates (1989). The PCR conditions used for screening fungal transformants for homologous recombination were $96^{\circ} \mathrm{C}$ for $2 \mathrm{~min}$, followed by $96^{\circ} \mathrm{C}$ for $30 \mathrm{~s}, 56^{\circ} \mathrm{C}$ for $30 \mathrm{~s}, 72^{\circ} \mathrm{C}$ for $1 \mathrm{~min}$ for 40 cycles, and $72^{\circ} \mathrm{C}$ for $5 \mathrm{~min}$. The primers used were MpdGPSf (5'-AACGCCA TCCAACGCCACAAC-3') and MpdGPSr (5'-GGATGTACTG CT TCTTCGCCTG-3').

Preliminary screening of fungal transformants was performed by spore PCR. Genomic DNA was extracted from spores as 
follows. A full loopful of transformant growth (including spores and mycelia) was scraped into $500 \mu \mathrm{l}$ of DNA extraction buffer $(0.5 \mathrm{M} \mathrm{NaCl}, 10 \mathrm{mM}$ Tris-HCl, $\mathrm{pH} 7.5,10 \mathrm{mM}$ EDTA, 1\% sodium dodecyl sulfate). The suspension was then placed at $-20^{\circ} \mathrm{C}$ and was allowed to freeze before thawing at $37^{\circ} \mathrm{C}$. After repeating the freeze-thawing, the suspension was centrifuged at $12,000 \times g$ for $15 \mathrm{~min}$ to remove cellular debris, and the supernatant was added to an equal volume of isopropanol. The precipitated DNA was collected by centrifugation at $12,000 \times g$ for 10 min and was washed once with $70 \%$ ethanol before being air-dried and resuspended in $10 \mu \mathrm{l}$ of sterile water. The resulting DNA solution $(2 \mu \mathrm{l})$ was used in the PCR, using the conditions listed above.

\section{Spore viability assays.}

The ability of spores to germinate following stress treatment was performed as follows. Spores $\left(10^{6}\right)$ were incubated at 50 or $40^{\circ} \mathrm{C}$ or in $1 \mathrm{mM} \mathrm{NaOCl}$, with $100-\mu$ l samples taken at 0 , $15,30,60$, and $120 \mathrm{~min}$. The $100-\mu \mathrm{l}$ aliquot was then diluted 10-, 100-, and 1,000-fold, and these dilutions were plated out onto CZV8CS plates (45.4 g of Czapek Dox agar [Oxoid, Hampshire, U.K.], $10.0 \mathrm{~g}$ of agar, $3.0 \mathrm{~g}$ of $\mathrm{CaCO} 3,200 \mathrm{ml}$ of Campbell's V8 juice, $20.0 \mathrm{~g}$ of casamino acids, $20 \mathrm{~g}$ of peptone, $20 \mathrm{~g}$ of yeast extract, $3 \mathrm{~g}$ of adenine, $0.02 \mathrm{~g}$ of biotin, $0.02 \mathrm{~g}$ of nicotinic acid, $0.02 \mathrm{~g}$ of $p$-aminobenzoic acid, $0.02 \mathrm{~g}$ of pyridoxine, $0.02 \mathrm{~g}$ of thiamine, and $15 \mathrm{~g}$ of agar per liter). The plates were incubated for 1 week in the conditions described above and the colonies were counted. Each dilution was plated out in duplicate and the experiment was performed twice.

\section{ACKNOWLEDGMENTS}

The authors would like to thank R. Lee for proofreading the manuscript and to acknowledge the financial support of the Grains Research and Development Corporation of Australia.

\section{LITERATURE CITED}

Aitken, W. B., Wright, J. R., and Le Tourneau, D. 1969. Mannitol biosynthesis in Pyrenochaeta terrestris. I. D-mannitol-1-phosphate: NAD oxidoreductase. Physiol. Plant 22:609-619.

Bathgate, J. A., and Loughman, R. 2001. Acospores are a source of inoculum of Phaeosphaeria nodorum, $P$. avenaria f. sp. avenaria and $M y$ cosphaerella graminicola in Western Australia. Aust. Plant Pathol. 30:317-322.

Benedikz, P. W., Mappledoram, C. J., and Scott, P. R. 1981. A laboratory technique for screening cereals for resistance to Septoria nodorum using detached seedling leaves. Trans. Brit. Mycol. Soc. 77:667-668.

Brown, A. T., and Bowles, R. D. 1977. Polyol metabolism by a caries-conducive Streptococcus: Purification and properties of a nicotinamide adenine dinucleotide-dependent mannitol-1-phosphate dehydrogenase. Infect. Immun. 16:163-173.

Chaturvedi, V., Bartiss, A., and Wong, B. 1996. Stress tolerance and pathogenic potential of a mannitol mutant of Cryptococcus neoformans. Microbiology 142:937-943.

Chaturvedi, V., Bartiss, A., and Wong, B. 1997. Expression of bacterial $\mathrm{mtlD}$ in Saccharomyces cerevisiae results in mannitol synthesis and protects a glycerol-defective mutant from high-salt and oxidative stress. J. Bacteriol. 179:157-162.

Clark, A. J., Blissett, K. J., and Oliver, R. P. 2003. Investigating the role of polyols in Cladosporium fulvum during growth under hyper-osmotic stress and in planta. Planta 216:614-619.

Daub, M. E., and Ehrenshaft, M. 2000. The photoactivated Cercospora toxin cercosporin: Contributions to plant disease and fundamental biology. Ann. Rev. Phytopathol. 38:461-490.

Dixon, K. P., Xu, J. R., Smirnoff, N., and Talbot, N. J. 1999. Independent signaling pathways regulate cellular turgor during hyperosmotic stress and appressorium-mediated plant infection by Magnaporthe grisea. Plant Cell 11:2045-2058.
Hankinson, O., and Cove, D. J. 1974. Regulation of the pentose phosphate pathway in the fungus Aspergillus nidulans. J. Biol. Chem. 249:23442353.

Holligan, P. M., and Jennings, D. H. 1972. Carbohydrate metabolism in the fungus Dendryphiella salina. The influence of different carbon and nitrogen sources on the accumulation of mannitol and arabitol. New Phytol. 71:583-594.

Hult, K., and Gatenbeck, S. 1978. Production of NADPH in the mannitol cycle and its relation to polyketide formation in Alternaria alternata. Eur. J. Biochem. 88:607-612.

Hult, K., and Gatenbeck, S. 1979. Enzyme activities of the mannitol cycle and some connected pathways in Alternaria alternata, with comments on the regulation of the cycle. Acta Chem. Scandin. Series B 33:239243.

Hult, K., Veide, A., and Gatenbeck, S. 1980. The distribution of NADPH regenerating mannitol cycle among fungal species. Arch. Microbiol. 128:253-255.

Jennings, D. B., Ehrenshaft, M., Pharr, D. M., and Williamson, J. D. 1998. Roles for mannitol and mannitol dehydrogenase in active oxygen-mediated plant defense. Proc. Natl. Acad. Sci. U.S.A. 95:15129-15133.

Jennings, D. B., Daub, M. E., Pharr, D. M., and Williamson, J. D. 2002. Constitutive expression of a celery mannitol dehydrogenase in tobacco enhances resistance to the mannitol-secreting fungal pathogen Alternaria alternata. Plant J. 32:41-49.

Joosten, M. H. A. J., Hendrickx, L. J. M., and de Wit, P. J. G. M. 1990 Carbohydrate composition of apoplastic fluids isolated from tomato leaves inoculated with virulent or avirulent races of Cladosporium fulvum (syn. Fulvia fulva). Neth. J. Plant Pathol. 96:103-112.

Lewis, D. H., and Smith, D. C. 1967. Sugar alcohols in fungi and green plants. New Phytol. 66:143-184.

Martin, F., Canet, D., and Marchal, J. P. $1985 .{ }^{13} \mathrm{C}$ nuclear magnetic resonance study of mannitol cycle and trehalose synthesis during glucose utilization by the ectomycorrhizal ascomycete Cenococcum graniforme. Plant Physiol. 77:499-502.

Noeldner, P. K. M., Coleman, M. J., Faulks, R., and Oliver, R. P. 1994. Purification and characterization of mannitol dehydrogenase from the fungal tomato pathogen Cladosporium fulvum (syn. Fulvia fulva). Physiol. Mol. Plant Pathol. 45:281-289.

Pfyffer, G. E., Hubscher, U., and Rast, D. M. 1989. Antibodies against the fungal enzyme mannitol dehydrogenase. Exp. Mycol. 13:321-331.

Ruijter, G. J. G., Bax, M., Patel, H., Flitter, S. J., van de Vondervoort, P. J. I., de Vries, R. P., vanKuyk, P. A., and Visser, J. 2003. Mannitol is required for stress tolerance in Aspergillus niger conidiospores. Eukaryotic Cell 2:690-698.

Sambrook, J., Fritsch, E. F., and Maniatis, T. 1989. Molecular Cloning: A Laboratory Manual. Cold Spring Harbor Laboratory Press, Cold Spring Harbor, NY, U.S.A..

Smirnoff, N., and Cumbes, Q. J. 1989. Hydroxyl radical scavenging activity of compatible solutes. Phytochemistry 28:1057-1060.

Solomon, P. S., Thomas, S. W., Spanu, P., and Oliver, R. P. 2003. The utilisation of di/tripeptides by Stagonospora nodorum is dispensible for wheat infection. Physiol. Mol. Plant Pathol. 63:191-199.

Solomon, P. S., Tan, K.-C., Sanchez, P., Cooper, R. M., and Oliver, R. P. 2004. The disruption of a G(alpha) subunit sheds new light on the pathogenicity of Stagonospora nodorum on wheat. Mol. Plant-Microbe Interact. 17:456-466.

Stoop, J. M. H., and Mooibroek, H. 1998. Cloning and characterization of NADP-mannitol dehydrogenase cDNA from the button mushroom, Agaricus bisporus, and its expression in response to $\mathrm{NaCl}$ stress. Appl. Env. Microbiol. 64:4689-4696.

Stoop, J. M. H., Williamson, J. D., and Pharr, D. M. 1996. Mannitol metabolism in plants: A method for coping with stress. Trends Plant Sci. 1:139-144.

Suvarna, K., Bartiss, A., and Wong, B. 2000. Mannitol-1-phosphate dehydrogenase from Cryptococcus neoformans is a zinc-containing longchain alcohol/polyol dehydrogenase. Microbiology 146:2705-2713.

Thines, E., Weber, R. W. S., and Talbot, N. J. 2000. MAP kinase and protein kinase A-dependent mobilization of triacylglycerol and glycogen during appressorium turgor generation by Magnaporthe grisea. Plant Cell 12:1703-1718.

Wang, S. C., and Le Tourneau, D. 1972. Mannitol biosynthesis in Sclerotinia sclerotiorum. Arch. Microbiol. 81:91-99.

Witteveen, C. F. B., and Visser, J. 1995. Polyol pools in Aspergillus niger. FEMS (Fed. Eur. Microbiol. Soc.) Microbiol. Lett. 134:57-61.

Yamada, H., Okamoto, K., Kodama, K., Moguchi, F., and Tanaka, S. 1961. Enzymatic studies on mannitol formation by Piricularia oryzae. J. Biochem. 49-55. 